\title{
The Children's Faecal Matter Structure Is Built by Their Parents
}

\author{
Eduardo Cueto Rua1, Ricardo Wright' ${ }^{2}$, Cecilia Zubiri³, Luciana Guzmán³, Claudia Losada1, \\ M. Inés Urrutia1, María T. Gonzalez ${ }^{3}$, Ricardo Drut ${ }^{4 *}$, Mariela Espósito ${ }^{3}$, Norberto Recalde ${ }^{5}$, \\ Jorge Fiad6, Ignacio Goñi' ${ }^{1}$ Natalia Belén' ${ }^{6}$ María Cristina Arregui1
}

\author{
${ }^{1}$ Facultad de Ciencias Médicas, Universidad Nacional de La Plata, La Plata, Argentina \\ ${ }^{2}$ Comisión de Investigación Científica de la Provincia de Buenos Aires, Buenos Aires, Argentina \\ ${ }^{3}$ Pediatric Hospital “Sor María Ludovica”, La Plata, Argentina \\ ${ }^{4}$ Universidad Nacional de La Plata, La Plata, Argentina \\ ${ }^{5}$ Consultant in Pediatrics, Mar del Plata City, Argentina \\ ${ }^{6}$ Dolores City, Argentina \\ Email: ^ricardodrut@yahoo.com
}

\footnotetext{
How to cite this paper: Cueto Rua, E., Wright, R., Zubiri, C., Guzmán, L., Losada, C., Urrutia, M.I., Gonzalez, M.T., Drut, R., Espósito, M., Recalde, N., Fiad, J., Goñi, I., Belén, N. and Arregui, M.C. (2019) The Children's Faecal Matter Structure Is Built by Their Parents. Open Journal of Epidemiology, 9, 64-74.

https://doi.org/10.4236/ojepi.2019.91006
}

Received: December 3, 2018

Accepted: January 21, 2019

Published: January 24, 2019

Copyright $\odot 2019$ by author(s) and Scientific Research Publishing Inc. This work is licensed under the Creative Commons Attribution International License (CC BY 4.0).

http://creativecommons.org/licenses/by/4.0/

Open Access

\begin{abstract}
Introduction: Humans have gone through physical changes over the last 4 million years. The mouth, however, has not changed teeth quantity or quality. Eight incisors for fruits, vegetables and tubers; four little canines for little animals; eight premolars and twelve flat molars are used for crushing these foods, especially whole grains and legumes. The teeth crushing foods are the first step in the building of faecal matter. Foods are selected mostly according to cultural guidelines than to biological needs. The patterns of consumption are induced by the publicity of industrialized or processed foods. Material and Methods: This study design was observational, analytical, correlational, transversal and prospective. One thousand children ( 0 - 12 years old) were questioned in order to learn about the relationship between Weekly Eating Frequency (WEF) and Faecal Matter (FM) characteristics. The FM was classified as soft, normal or hard and the outcome was expressed as Dry Faecal Residue (DFR). The WEF and Weekly Bowel Movement Frequency (WBMF) were determined and tabulated according to times per week. Environmental factors, parents' education level and children's birth order were examined. Results: There was a strong association between DFR, WBMF and WEF. Environment and education level did not play a key role although birth order did matter. Conclusions: Fibre-free foods (dairies, meats, flours and sweeties or sodas) increased DFR. Foods containing fibre from vegetables decreased DFR, which in turn contributed to the WBMF. Lowest DFR was observed in children under Exclusive Breastfeeding (EB). Distant last-born children had higher DFR. Comments: Daily examples support these results
\end{abstract}


and it is clear that children's FM is built by their parents. We encourage parents to follow the "mouth nature" rather than the "advertisements nature".

\section{Keywords}

Bowel Movement Frequency, Constipation, Culture, Faecal Matter, Foods

\section{Introduction}

Primates have eyes in one plane, an opponent finger and clavicles. These allowed the versatility of arms and, together with the standing, remark the difference [1].

Since Ardipithecus all species had teeth similar in quality and number to that of modern man. Our mouth has had for millions of years, eight incisors to eat fruits, vegetables and tubers; four canines, which are similar in size to the incisors, to eat little animal; eight premolars and twelve flat molars, which crush all, particularly grains and legumes [2] [3] [4].

Actual feeding left variety to be a "universal" and routine habit [5].

Children left chewing fruits for just "swallowing" soft, sweet and flavored desserts. The word milk has replaced the words breakfast and snack.

We then asked ourselves if foods are related to the teeth of to the advertisements.

The aim of present paper is to understand the relationships between ingested food and the characteristics, consistency and frequency of depositions in children between 0 and 12 years of age. We made 1000 surveys.

\section{Material and Methods}

The surveys were done in the year 2012, in pediatric doctor's offices, schools, and kinder gardens at La Plata city (51.5\%) Mar del Plata city (24.2\%) and Dolores city (10.1\%). Other were done at Berisso city, Ensenada city, Etcheverry city, Roque Pérez city and Lobos city, these representing $14.2 \%$ of the sample. The study was observational, analytic, correlational, transversal y prospective.

\subsection{Sample}

Confidence level was 95\% ( $\alpha=0.05)$. The probabilistic evaluation of the size of the sample showed a minimal number of 664 children $(15,625.084$ inhabitants) [6]. The whole study included a total of 1000 children in order to produce a larger reliability to the results. To include the children in this study it was taken in consideration that they come to a periodic clinical control, or assist to kindergarten or schools in the Buenos Aires Province, and that they did not present any acute or chronic condition. Children out of these situations were excluded.

\subsection{Instruments for Data Collection}

We used a structured inquiry with closed answers containing: 


\subsubsection{Personal Data}

First letter of name and surname, sex, age in years or in months when less than one year of age. Once the healthy child coming to clinical control was identified the objective was to establish the consistence of the faecal matter and the frequency of depositions.

\subsubsection{Breastfeeding}

This item was performed to breastfeeders with exclusive maternal (EM) or mixed, complemented with cow milk (CM), being it "formula" or common one, at least once a day.

\subsubsection{Feeding Habits (FH)}

An inquiry of FH of 7 days was used. This presented a numeric scale defined as: 0 , never; 1 , once; 4 , four times; 7 , seven times per weeks and 14 , twice a day. The analyzed foods included: CM; yogurt or desserts; cheeses; meats (cow, bird, fish, pork or lamb); starchs (flours, pasta, rice, potato or sweet potato); sodas or juices; candies (caramel cookie, chocolates or candies); carotenes (pumpkin o carrots); green leaves vegetables; vegetables and fruits.

\subsubsection{Consistency of the Faecal Matter (FM)}

The categories of FM consistency in DFR was proposed by one of the AA due to his experience while doing his doctoral thesis [7], and due to the fact of having done 5000 Van de Kamer and chemical-functional analysis as diagnostic tool in the malabsorption syndrome

The consistency was reported by the parents. For this the inquirer used the raw meat (RM) consistency as a reference tool. This was taken as that of normal FM or Bristol $3-4$. The RM and the normal FM have dry residue similar to that of water [8]. Beginning with this premise, parents were asked if it was softer or harder than that of RM [9] [10].

If the answer was softer (pasty-amorphous or Bristol 5 - 6), the register for DFR was $10 \%$.

If the answer was harder (difficult to deform or Bristol $1-2$ ), the register for DFR was $30 \%$.

\subsubsection{Weekly Evacuation Frequency (WEF)}

The WEF established as $0,1,2,4,7$ and 14 times per week, 0 being an evacuation in more than 7 days, and 14 belonging to those evacuating more than once per day.

As to the ambient aspects, the water was categorized as 1-drinking water. 2-water wells 3-water carried, and the excretions as 1-sewer, 2-well 3-open sky. Instruction level was evaluated from 0 to 18 years of studies, where 0 meant uneducated, 7: 7th primary school grade, 12: secondary school, 14: universitary incomplete, and 18: graduated.

\subsubsection{Time of Birth}

The time of birth as related to the brothers and sisters was established as first, 
middle last, one and only, and "last but distant" (the child distant 6 years or more from the precedent). We know that these kids get a special treatment [11] [12].

Once that faecal matter consistency and evacuation frequency were established the objective was to determine the "quality" and "frequency" of foods. The inquiry was simple to understand and easy to fill by the clinicians as well as by the nutritionists doing it (see Adnexa).

\subsubsection{Data Analysis}

The results were registered in an Epi6 base and analised through descriptive and inferencial statistic methods. Particularly, the mean value of each parameter in the different groups was statistically analised by the Varianza Analysis (ANOVA).

When differences between the compared means were found the analysis was continued with a Minimal significant differences (m.s.d.) test and the Tukey test was used.

The process of data observation followed the analysis of FM consistency as related to WEF, EM, weekly food frequency (WFF) and mixed; and some cultural aspects.

We decided to use the quantified data of the FM consistency and not the adjective of soft, normal or hard, or the Bristol equivalents.

The weekly food frequency WFF of the following was evaluated: CM, yogurt, meats, starches (flours), sodas, candies, carotenes, vegetables of green leaves, vegetables and fruits; and at the same time the frequency of EM and the consistency of depositions.

\section{Results}

\subsection{Population}

From the whole population submitted to the inquiry $76.9 \%$ was in clinical control, $20.2 \%$ was in the healthy child consulting room, and $2.9 \%$ in the school and kinder garden; $50.3 \%$ were girls, with a mean age of $3.85 \pm 3.26$ years, while $49.7 \%$ were boys with a mean age of $4.15 \pm 3.41$ years. While comparing the mean age by sex we found a " $\mathrm{t}$ " $=-1.422(\mathrm{P}=0.155)$.

The whole group had a fecal dry residue (FDR) of $20.49 \pm 6.51$ and a WFF of $7.22 \pm 4.15$. The overall mean of FDR in both sexes was a normal FM with a " $t$ " $=0.505(\mathrm{P}=0.614)$ and " $\mathrm{t}$ " $=-1.218(\mathrm{P}=0.224)$, respectively. Particularly, $18.6 \%$ of FM was "soft" (FDR of 10\%); 57.6\% "normal" (FDR of 20\%) and $23.8 \%$ "hard" (FDR of 30\%).

\subsection{Fecal Dry Residue}

When evaluating together the FDR and FES it clearly appears the close relationship between the two variables $\mathrm{Chi}^{2}=395.44$ ( $\left.\mathrm{P} \leq 0.001\right)$. When the FDR increased the WEF decreased significantly, and vice versa. While observing the extreme values it appears that with a FDR of $28.27 \%$, (hard FM) the evacuation are 
twice per week while with a FDR of $16.02 \%$, (soft FM) the evacuations are twice per day.

FES was arranged in 4 categories according to the weekly frequency and when comparing the means of FDR for each of these categories the ANOVA resulted with an $\mathrm{F}=134.79(\mathrm{P}=0.00000)$, a highly significant difference. When WEF increased there appears an important decreasing of FDR values.

\section{FDR and LME}

If the group with breast feeding only EM was compared with that receiving mixed milk feeding it appeared that the FDR increased from $11.09( \pm 3.15)$ to $16.64( \pm 7.06)$, respectively, the differences being highly significant $(" \mathrm{t}$ " $=-5.580$ $(\mathrm{P} \leq 0.001))$.

\subsection{Dry Residue and Feeding Frequency}

The analysis of the different frequencies of feeding showed a sequence of 14, 7, 4 $\mathrm{y}$ once a week. As presented in Table 1 foods without fibers in the frequencies of 14 and 7 are mainly milky, producing a high FDR, therefore inducing constipation. On the contrary, products with vegetable fibers given with the same frequency generate a los FDR, and so a soft FM. To be particularly highlighted are foods offered to children in frequency 4 (every second day) which produced a

Table 1. Dry faecal residue and weekly feeding frequency.

\begin{tabular}{|c|c|c|c|c|}
\hline Order & $\begin{array}{c}\text { Food } 14 \\
\text { DFR ranking }\end{array}$ & $\begin{array}{c}\text { Food } 7 \\
\text { DFR ranking }\end{array}$ & $\begin{array}{c}\text { Foods } 4 \\
\text { DFR Ranking }\end{array}$ & $\begin{array}{c}\text { Foods } 1 \\
\text { DFR Ranking }\end{array}$ \\
\hline \multirow{2}{*}{1} & Cheeses (18) & candies-sodas (98) & Cheeses (311) & Fruits (140) \\
\hline & $25.00 \pm 6.18$ & $24.72 \pm 6.01$ & $21.74 \pm 5.16$ & $23.86 \pm 6.30$ \\
\hline \multirow{2}{*}{2} & Yogurts (178) & Cheeses (145) & candies-sodas (78) & Vegetables (315) \\
\hline & $23.88 \pm 8.12$ & $23.24 \pm 5.88$ & $21.67 \pm 3.75$ & $22.42 \pm 6.24$ \\
\hline \multirow{2}{*}{3} & candies-sodas (89) & Flours (348) & Meats (359) & Carotens (264) \\
\hline & $22.02 \pm 6.06$ & $22.25 \pm 6.06$ & $21.56 \pm 5.67$ & $22.31 \pm 6.01$ \\
\hline \multirow{2}{*}{4} & Flours (139) & Meats (366) & Carotenes (367) & Cheeses (234) \\
\hline & $21.37 \pm 5.80$ & $21.92 \pm 5.81$ & $21.36 \pm 5.56$ & $21.04 \pm 5.72$ \\
\hline \multirow{2}{*}{5} & CM (444) & Yogurts (344) & CM (105) & candies-sodas (39) \\
\hline & $21.08 \pm 6.60$ & $21.80 \pm 5.79$ & $21.43 \pm 4.48$ & $21.03 \pm 4.47$ \\
\hline \multirow{2}{*}{6} & Meats (79) & CM (198) & Fruits (281) & Legumes (315) \\
\hline & $20.25 \pm 6.40$ & $21.48 \pm 6.35$ & $21.35 \pm 5.88$ & $20.90 \pm 5.24$ \\
\hline \multirow{2}{*}{7} & Fruits (63) & Fruits (366) & Flours (363) & CM (117) \\
\hline & $19.36 \pm 6.19$ & $20.72 \pm 5.31$ & $21.16 \pm 5.78$ & $20.85 \pm 5.50$ \\
\hline \multirow{2}{*}{8} & Carotenes (7) & Carotenes (103) & Vegetables (270) & Meats (68) \\
\hline & $18.57 \pm 6.90$ & $19.81 \pm 6.26$ & $20.74 \pm 4.82$ & $20.59 \pm 6.66$ \\
\hline \multirow{2}{*}{9} & \multirow{2}{*}{ Vegetables $(0)$} & Vegetables (59) & Legums (68) & Yogurts (126) \\
\hline & & $18.30 \pm 6.47$ & $20.59 \pm 4.19$ & $20.32 \pm 5.92$ \\
\hline \multirow{2}{*}{10} & \multirow{2}{*}{ Legumes (0) } & Legumes (14) & Yogurts (203) & Flours (39) \\
\hline & & $17.86 \pm 8.02$ & $20.21 \pm 5.21$ & $18.97 \pm 5.52$ \\
\hline Statistics & $\begin{array}{c}F=6.23 \\
(P \leq 0.001)\end{array}$ & $\begin{array}{c}F=9.55 \\
(P \leq 0.001)\end{array}$ & $\begin{array}{c}F=1.75 \\
(P=0.073)\end{array}$ & $\begin{array}{c}F=6.19 \\
(P \leq 0.001)\end{array}$ \\
\hline
\end{tabular}

DFR: Dry Faecal Residue. CM: Cow Milk. 
normal and homogeneous FDR, clearly seen by a non-significant difference. Foods given with a frequency once a week produced the expected effect: If scant fibers the FDR tends to be high and if scant milky products the FDR tends to be low.

In the analysis of consumed foods decreasing FDR it appears flours, meats and fruits, followed by yogurt and in the last three positions natural foods with fibers (Table 2).

\subsection{Weekly Evacuation Frequency (WEF)}

The WEF analysis showed that $89.2 \%$ of the children evacuated once every 2 days, daily and twice per day was, while only $10.3 \%$ evacuated every three days and the only evacuating once in more than 7 days was a child the with EM.

Table 3 shows that children with soft FM evacuated a mean of 10.32 times/week while those with normal FM did it daily and those with hard FM did it 4.15 times/week, the differences being highly significant (ANOVA, $F=153.35$ $(P=0.00000)$ ). The higher the FDR the lower the WEF.

As related to the WFF and the EM and the mixed, it was observed that the former evacuated 10.4 times per week while the latter did so 8.68 times. Comparing the means of both groups showed a Student " $t$ " $=2.36(\mathrm{P}=0.019)$, indicating a significant difference between the WFF and the EM and mixed.

The analysis of the different WEF and the WFF showed a strong association between both (Table 4).

Table 2. Ranking of the more consumed foods.

\begin{tabular}{ccc}
\hline Ranking & Food & Frequency \\
\hline 1 & Flours & 2 \\
2 & Meat & 16 \\
$\mathbf{3}$ & Fruits & 43 \\
$\mathbf{4}$ & Yogur & 44 \\
$\mathbf{5}$ & CM & 61 \\
$\mathbf{6}$ & Candies and Sodas & 88 \\
7 & Cheese & 149 \\
$\mathbf{8}$ & Carotenes & 153 \\
9 & Vegetables & 219 \\
10 & Legumes & 446 \\
\hline
\end{tabular}

Table 3. Weekly Evacuation Frequency (WEF) as related to the Faecal Dry Residue (FDR).

\begin{tabular}{cccc}
\hline & Mean WEF & S.D & Number \\
\hline FDR 10 & 10.323 & 4.311 & 186 \\
FDR 20 & 7.491 & 3.779 & 576 \\
FDR 30 & 4.152 & 2.557 & 237 \\
\hline
\end{tabular}


Table 4. Weekly evacuation frequency and weekly feeding frequency.

\begin{tabular}{|c|c|c|c|c|}
\hline Order & $\begin{array}{c}\text { Food } 14 \\
\text { Ranking WEF }\end{array}$ & $\begin{array}{c}\text { Food } 7 \\
\text { Ranking WEF }\end{array}$ & $\begin{array}{c}\text { Food } 4 \\
\text { Ranking WEF }\end{array}$ & $\begin{array}{c}\text { Foods } 1 \\
\text { Ranking WEF }\end{array}$ \\
\hline \multirow{2}{*}{1} & Meats (77) & Fruits (330) & Legumes (62) & Flours (32) \\
\hline & $8.79 \pm 4.07$ & $7.16 \pm 3.88$ & $6.81 \pm 3.51$ & $7.62 \pm 3.97$ \\
\hline \multirow{2}{*}{2} & Carotens (5) & Meats (339) & Yogurts (173) & Cheeses (215) \\
\hline & $8.40 \pm 3.13$ & $7.06 \pm 3.86$ & $6.68 \pm 3.51$ & $7.36 \pm 3.82$ \\
\hline \multirow{2}{*}{3} & Fruits (60) & Vegetals (50) & Fruits (257) & Yogurts (118) \\
\hline & $8.23 \pm 3.58$ & $6.94 \pm 3.44$ & $6.37 \pm 3.69$ & $6.99 \pm 3.54$ \\
\hline \multirow{2}{*}{4} & Candies-sodas (89) & Flours (327) & Vegetals (250) & Meats (55) \\
\hline & $8.19 \pm 4.23$ & $6.91 \pm 3.82$ & $6.37 \pm 3.46$ & $6.74 \pm 3.84$ \\
\hline \multirow{2}{*}{5} & Flours (133) & Carotenes (81) & Carotenes (332) & Carotenes (245) \\
\hline & $7.95 \pm 4.06$ & $6.81 \pm 3.45$ & $6.24 \pm 3.72$ & $6.68 \pm 3.98$ \\
\hline \multirow{2}{*}{6} & CM (387) & Yogurts (316) & Flours (322) & Legumes (294) \\
\hline & $7.62 \pm 4.11$ & $6.77 \pm 3.95$ & $5.76 \pm 3.57$ & $6.41 \pm 3.69$ \\
\hline \multirow{2}{*}{7} & Cheeses (18) & Cheeses (143) & Meats (329) & Vegetals (297) \\
\hline & $6.67 \pm 4.51$ & $6.26 \pm 4.13$ & $5.69 \pm 3.46$ & $6.61 \pm 4.16$ \\
\hline \multirow{2}{*}{8} & Yogurts (165) & $\mathrm{CM}(170)$ & Cheeses (291) & Fruits (126) \\
\hline & $5.68 \pm 4.03$ & $6.24 \pm 3.45$ & $5.62 \pm 3.74$ & $5.30 \pm 3.36$ \\
\hline \multirow{2}{*}{9} & \multirow{2}{*}{ Legumes $(0)$} & Legumes (14) & $\mathrm{CM}(93)$ & Candies-Soda (39) \\
\hline & & $5.36 \pm 1.781$ & $5.20 \pm 2.97$ & $5.08 \pm 2.62$ \\
\hline \multirow{2}{*}{10} & \multirow{2}{*}{ Vegetals $(0)$} & Candies-Sodas (98) & Candies-Sodas (77) & CM (105) \\
\hline & & $4.82 \pm 2.75$ & $4.23 \pm 1.95$ & $4.29 \pm 2.02$ \\
\hline Statistics & $\begin{array}{c}F=6.85 \\
(P \leq 0.001)\end{array}$ & $\begin{array}{c}\mathrm{F}=4.29 \\
(\mathrm{P}=0.000015)\end{array}$ & $\begin{array}{c}F=5.54 \\
(P \leq 0.001)\end{array}$ & $\begin{array}{c}F=8.13 \\
(P \leq 0.001)\end{array}$ \\
\hline
\end{tabular}

CM: Cow Milk.

\subsection{Cultural Variables and FDR}

Mothers' instruction level was $11.28 \pm 4.30$ and that of the fathers $11.03 \pm 4.27$, ( $4^{\circ}$ year at the secondary school). If this instruction level is related to the FDR this did not modified significantly. Although the FDR increased with the instruction level the ANOVA test with a value of $\mathrm{F}=2.46(\mathrm{P}=0.06)$ resulted in a non-significant number.

The analysis of the DFR as related to the birth order showed different means. The "last" category presented the lower DFR, most probably due to the EM. This contrasted with the category "last but distant" which showed the higher DFR (Table 5).

This Table shows all the DFR in normal values but according to our experience we believe there is a difference in de FM of brothers as a whole (1 - 2 - 3: FDR $=20.43 \pm 6.28$ ) when compared with one only (4) and "last but distant" (34).

The ANOVA analysis of these means showed a value of $F=3.71(P=0.025)$, supporting our presumption. This difference is related to the "last but distant" son with the other two groups, these not presenting differences between them. 
Table 5. Sons order and faecal dry residue.

\begin{tabular}{lcccc}
\hline \multicolumn{1}{c}{ Order } & FDR 10 & FDR 20 & FDR 30 & Mean \pm SD FDR \\
\hline 1) First $\mathbf{n}=\mathbf{2 9 5}$ & 27 & 191 & 77 & $21.60 \pm 5.78$ \\
2) Meddle $\mathbf{n}=\mathbf{2 0 1}$ & 20 & 137 & 45 & $21.24 \pm 5.55$ \\
3) Last $\mathbf{n}=\mathbf{2 7 5}$ & 87 & 140 & 48 & $18.58 \pm 6.87$ \\
4) Only $\mathbf{n}=\mathbf{1 8 0}$ & 45 & 88 & 47 & $20.11 \pm 7.17$ \\
34) Last but distant $\mathbf{n}=\mathbf{4 8}$ & 7 & 20 & 21 & $22.92 \pm 7.13$ \\
\hline
\end{tabular}

FDR: Faecal Dry Residue.

The sanitary environment seemed not to influence DFR. Different water sources and residues elimination maintained a normal DFR (Table 6). When comparing the three means with the ANOVA the result was $\mathrm{F}=1.21(\mathrm{P}=0.321)$ indicating a non-significant difference in the DFR. So then, it is evident that the environment in this sample did not influence in DFR. It should be noted that there are "private neighborhoods" that have water pump and waterhole wells, but with a strict sanitary control.

\section{Discussion}

\subsection{FDR}

It is known that the WEF is related to the FDR as well as to cultural guidelines. In order to perform this investigation we considered more truthfully the FDR-consistency than the WEF, since although related, the first seems to depend exclusively on the food culture and the second adds the social guidelines. "Not always that you want you can (large) and not always that you want and may, you should (visits)".

Notice that the area for FM and urine evacuations is referred as "bath rooms".

To demonstrate that the FDR and the WEF condition themselves mutually we recurred to a peculiar example. There are scientific papers referring people carrying packs (and hard) of drugs in the rectum [13] [14] and travel without evacuation emergencies. On the contrary an enema generates this urgency.

\subsection{Foods}

The most consumed foods were: flours, meats fruits and yogurts. Vegetables were absent in $44.6 \%$ of the responses even the bible mandate [15] and the work of Daniel, without double blind but with a control group [16].

As seen, the flours, excluding lactating children, were consumed by $99.8 \%$ of the children. Citing the chronicler Facundo Sonatti: "In the morning toasts, the pastas of noon and the crackers in the afternoon the wheat are present every day in the Argentine menu... The flours consumption was 94 kilograms per capita in 2012, according to data from the Federación Argentina de la Industria Molinera" [17]. 
Table 6. Relationship between faecal dry residue and sanitary categories.

\begin{tabular}{rccc}
\hline Sanitary categories & Mean FDR & SD & N \\
\hline Water 1 excretas 1 & 22.63 & 8.28 & 649 \\
Water 2 excretas 2 & 20.98 & 8.00 & 61 \\
Water 3 excretas 3 & 22.00 & 11.83 & 10 \\
\hline
\end{tabular}

FDR: Faecal Dry Residue.

As related to meat we transcribe a journalist note of year 2013: "What is certain is that in Argentina never was eaten so large quantity of meat as now, 116.6 kilograms per year and per capita... All according to the Ministry of Agriculture" [18].

Water represents $75 \%$ of faecal matter weight and is related to food. A mixed nutritional regimen eliminates 60 to 250 grams/day, a vegetarian one $370 \mathrm{~g}$ and a meat-centered one between $54.5 \mathrm{~g}$ and $64 \mathrm{~g}$ [19].

The yogurt which is related by the present work as well as by our experience in the increasing of FDR, was present, excluding on EM, in the $94.5 \%$ of children. Hard FM is the first step to a painful deposition [20] and was present in $23.8 \%$ of the children, particularly in those consuming scant fiber and many milky products.

\subsection{Weekly Evacuation Frequency}

In 1775, Alexander Cumming designed and patented the toilet. This structure previously "away from" began to be integrated to home [21]. However, cultural features keep on considering bowel evacuation as highly private and a bit shaming. Our work is to demystify this function which is with us since the origin of life itself.

\subsection{Cultures}

The order of the birth of the sons according appears as a risk factor to be taken into consideration. To the last but distant son occasionally is referred as a "sky present". With this child the parents' behavior frequently is permissive. In this study the last but distant was besides the main soda consumer. It seems that because it was not searched for parents feel enabled to make of him/her an obese, constipated and dental caries suffering child [22]. In our experience is also the one who more transgress the celiac diet [23].

There are many other variables which might be crossed. Among them, selection of fruits and vegetables "once" a week compared with yogurt and cow milk "twice a day", there were only 9 children and all of them had hard FM. We all know that cheese constipates and that there is no aleatory, double blind and controlled scientific research saying that water calms thirst but indeed it calms the thirst. Not always the experience requires evidences. 


\subsection{Miscellanies}

If mother's instruction is crossed with soda and candies consumption it appears clearly, and statistically significant, that the former is inversely proportional to the consumption of these products $\left(\mathrm{Chi}^{2} 123.64(\mathrm{P} \leq 0.001)\right)$. We can state that the consumption of a lot of sodas also do that with candies $\left(\mathrm{Chi}^{2}=693(\mathrm{P} \leq\right.$ $0.001)$ ). When less school more kiosk. As an illustrative data, we know that in Argentina the consumption of caramel cookies is 900.000 .000 per year [24]. Finally, if the levels of instruction of the parents are crossed between them $\left(\mathrm{Chi}^{2}=\right.$ 2203 ( $\mathrm{P} \leq 0.001)$ ) it appears evident that couples establish besides by "love" also by similar "culture and instruction level".

By last, we want to underline the results of column " 4 " of Table 5, where it can be seen that those who eat all foods on alternate days maintained a normal DFR normal. This frequency, "alternate days" would be a "healthy habit" and just by itself justifies this paper.

It is clear that children's FM results from parents building. These should take the guides more from human mouth nature than that of publicities.

\section{Conflicts of Interest}

The authors declare no conflicts of interest regarding the publication of this paper.

\section{References}

[1] Tudge, C. (2008) El Eslabón. Ed. Debate, Buenos Aires.

[2] Kimbel, W.H., Suwa, G., Asfaw, B., Rak, Y. and White, T.D. (2014) Ardipithecus Ramidus and the Evolution of the Human Cranial Base. Proceedings of the National Academy of Sciences of the United States of America, 111, 948-953. https://doi.org/10.1073/pnas.1322639111

[3] Scott, J.E., McAbee, K.R., Eastman, M.M. and Ravosa, M.J. (2014) Experimental Perspective on Fallback Foods and Dietary Adaptations in Early Hominins. Biology Letters, 10, Article ID: 20130789. https://doi.org/10.1098/rsbl.2013.0789

[4] Villmoare, B., Kuykendall, K., Rae, T.C. and Brimacombe, C.S. (2013) Continuous Dental Eruption Identifies Sts 5 as the Developmentally Oldest Fossil Hominin and Informs the Taxonomy of Australopithecus africanus. Journal of Human Evolution, 65, 798-805. https://doi.org/10.1016/j.jhevol.2013.09.007

[5] Britos, S., Saraví, A. and Villella, F. (2010) Buenas prácticas para una alimentación saludable de los Argentinos. Fundación Bunge y Born, Buenos Aires.

[6] INDEC (2010) Visto en. https://es.wikipedia.org/wiki/Censo.argentino_de_2010

[7] Cueto Rua, E.A. (1977) Valores normales de sodio, potasio, residuo seco agua, grasas, nitrógeno en heces de niños normales menores de dos años y medio. Tesis doctoral. aprobada. Presentada en la Facultad de Medicina de la Universidad Nacional de La Plata. Disponible, Página 17. No publicada.

[8] Hernández Rodríguez, M. and Sastre Gallego, A. (1999) Tratado de Nutrición. Capítulo 23. Editorial Díaz de Santos SA, Madrid.

[9] Lewis, S.J. and Heaton, K.W. (1997) Stool Form Scale as a Useful Guide to Intestinal 
Transit Time. Scandinavian Journal of Gastroenterology, 32, 920-924. https://doi.org/10.3109/00365529709011203

[10] Parés, D., Comas, M., Dorcaratto, D., Araujo, M.I., Vial, M., Bohle, B., et al. (2009) Adaptation and Validation of the Bristol Scale Stool form into Spanish Language among Health Professional and Patients. Revista Española de Enfermedades Digestivas, 101, 312-316. https://doi.org/10.4321/S1130-01082009000500002

[11] Cueto Rua, E.A. and Miculán, S. (2008) Constipación y Encopresis. Ludovica Pediátrica, 2, 71-73.

[12] Cueto Rua, E.A. (2011) Estreñimiento. Una epidemia programada. Revista Gastrohnup, 13, 58-65.

[13] Schaper, A., Hofmann, R., Bargain, P., Desel, H., Ebbecke, M. and Langer, C. (2007) Surgical Treatment in Cocaine Body Packers and Body Pushers. International Journal of Colorectal Disease, 22, 1531-1535. https://doi.org/10.1007/s00384-007-0324-9

[14] Berger, F.H., Nieboer, K.H., Goh, G.S., Pinto, A. and Scaglione, M. (2015) Body Parking a Review of General Background, Clinical and Imaging Aspects. Radiologia Medica, 120, 118-132. https://doi.org/10.1007/s11547-014-0458-0

[15] Antiguo Testamento (1960) Libro Génesis. Versículo 29. "He aquí os he dado toda hierba sembradera..."

[16] Testamento, A. and Daniel, L. Te ruego que hagas la prueba con tus siervos por diez días, y nos den legumbres a comer...

[17] Sonatti, F. (2015) Radiografía del consumo del pan en la mesa de los argentinos. http://www.apertura.com/negocios/Radiografia-del-consumo-del-pan-en-la-mesa-d e-los-argentinos-20130704-0001.html

[18] Longoni, M. (2013) El consumo de carnes creció 8\% y está en un nivel récord. http://www.clarin.com/politica/consumo-carnes-crecio-nivel-record_0_998300208. $\underline{\mathrm{html}}$

[19] Documenta Geigy (1965) Tablas científicas. Sexta edición, Metabolismo del agua y los electrolitos, 553.

[20] Cueto Rua, E.A. (2009) Constipación, ambiente y cultura. Una epidemia programada. Revista del ITAES, 11, 6-29.

[21] Alexander Cumming. http://www.historyofparliamentonline.org/volume/1690-1715/member/cumming-si r-alexander-1670-1725

[22] Than, N.N. and Newsome, P.N. (2015) A Concise Review of Non-Alcoholic Fatty Liver Disease. Atherosclerosis, 239, 192-202.

[23] Cueto-Rúa, E., Guzmán, L., Zubiri, C., Nanfito, G.I., Urrutia, M.I. and Mancinelli, L. (2013) Análisis de aceptabilidad, aspectos culturales e impacto personal del diagnóstico. En Rodrigo L y Peña AS, editores. Enfermedad celíaca y sensibilidad al gluten no celíaca. OmniaScience, Barcelona, 407-431. https://doi.org/10.3926/oms.167

[24] Manzoni, C. (2015) El alfajor es un líder imbatible en el mundo de las golosinas y cada vez se vende más. http://www.lanacion.com.ar/1764674-el-alfajor-es-un-lider-imbatible-en-el-mundo -de-las-golosinas-y-cada-vez-se-vende-más 